ISSN 2311-4495

ISSN 2410-5155 (Online)

УДК 618.3

\section{СИНДРОМ ГИБЕЛИ ОДНОГО ПЛОДА ПРИ МНОГОПЛОДНОЙ БЕРЕМЕННОСТИ}

\author{
Кузнецов А. А. ${ }^{1,3}$, Романовский А. Н., ${ }^{1,5}$, Шлыкова А. В. ${ }^{1,2}$, \\ Каштанова Т. А. ${ }^{1}$ Шман В. В. ${ }^{1}$, Кянксеп И. В. ${ }^{1}$, Мовчан В. Е. ${ }^{2}$, \\ Державина Н. Е. ${ }^{1}$, Савельева А. А. ${ }^{1}$, Овсянников Ф. А. ${ }^{4}$, \\ Михайлов А. В. ${ }^{1,2}$
}

${ }^{1}$ Санкт-Петербургское государственное бюджетное учреждение здравоохранения «Родильный дом № 17», Санкт-Петербург, Россия ${ }^{2}$ Федеральное государственное бюджетное образовательное учреждение высшего образования «Северо-Западный государственный медицинский университет имени И. И. Мечникова» Министерства здравоохранения Российской Федерации, Санкт-Петербург, Россия ${ }^{3}$ Федеральное государственное бюджетное образовательное учреждение высшего образования «Первый Санкт-Петербургский государственный медицинский университет имени академика И. П. Павлова» Министерства здравоохранения Российской Федерации, Санкт-Петербург, Россия ${ }^{4}$ Федеральное государственное бюджетное учреждение «Национальный медицинский исследовательский центр имени В. А. Алмазова» Министерства здравоохранения Российской Федерации, Санкт-Петербург, Россия ${ }^{5}$ Федеральное государственное бюджетное образовательное учреждение высшего образования «Санкт-Петербургский государственный университет», Санкт-Петербург, Россия
Контактная информация: Кузнецов Александр Александрович, СПб ГБУЗ «Родильный дом № 17», ул. Леснозаводская, д. 4/1, СанктПетербург, Россия, 192174. E-mail: a.a.kuznetsov03@gmail.com

Статья поступила в редакциюю 25.02.2019 и принята к печати 01.09.2019.

\footnotetext{
Резюме

Гибель одного плода в течение многоплодной беременности встречается с частотой от 3,7 до 6,8 \% и сочетается с увеличением вероятности преждевременных родов, гибели выживших плодов, а также с повышением уровней заболеваемости и смертности впоследствии среди родившихся новорожденных. Основными факторами, которые определяют перинатальные показатели при многоплодной беременности в случае антенатальной гибели одного плода, являются срок беременности на момент его гибели и тип многоплодия. Частота антенатальной гибели второго плода различна в зависимости от типа хориальности, составляя 4 \% при дихориальном многоплодии и достигая $12 \%$ при монохориальном многоплодии. В настоящее время при синдроме гибели одного плода (СГОП) взаимосвязь между типом хориальности, сроком родоразрешения и частотой преждевременных родов однозначно не установлена. Риск развития неврологических осложнений у новорожденных после антенатальной гибели одного плода существенно различается в зависимости от типа хориальности и составляет при монохориальных двойнях 18 \% и лишь 1 \% при дихориальных двойнях. В работе обсуждены основные причины гибели плода при многоплодной беременности в зависимости от типа хориальности, а также патофизиологические аспекты перинатальной заболеваемости и смертности в отношении второго плода. Представлены тактики ве-
} 
дения возможных осложнений, способы их коррекции, оптимальные методы и время родоразрешения при многоплодной беременности при СГОП.

Ключевые слова: синдром гибели одного плода, антенатальная гибель плода, многоплодная беременность.

Для ичитирования: Кузнецуов А.А., Романовский А.Н., Шлькова А.В. и др. Синдром гибели одного плода при многоплодной беременности. Транслячиионная медищина. 2019;6(5):31-38.

\title{
SINGLE FETAL DEMISE IN MULTIPLE PREGNANCY
}

\author{
Kuznetsov A. A. ${ }^{1,3}$, Romanovsky A. N. ${ }^{1,2,5}$, Shlykova A. V. ${ }^{1,2}$, \\ Kashtanova T. A. ${ }^{1}$, Shman V. V. ${ }^{1}$, Kyanksep I. V. ${ }^{1}$, Movchan V. E. ${ }^{2}$, \\ Derzhavina N. E. ${ }^{1}$, Savel'eva A. A. ${ }^{1}$, Ovsyannikov F. A. ${ }^{4}$, \\ Mikhailov A. V., ${ }^{1,2}$ \\ 'Saint Petersburg State “Maternity Clinic № 17”, Saint Petersburg, \\ Russia \\ ${ }^{2}$ North-Western State Medical University named after I. I. Mechnikov, \\ Saint Petersburg, Russia \\ ${ }^{3}$ Federal State Budgetary Education Institution of Higher Education \\ «Academician I. P. Pavlov First Saint Petersburg State Medical \\ University» of Ministry of Healthcare of the Russian Federation, Saint \\ Petersburg, Russia \\ ${ }^{4}$ Almazov National Medical Research Centre, Saint Petersburg, Russia \\ ${ }^{5}$ Federal State Budgetary Education Institution of Higher Education \\ «Saint-Petersburg State University», Saint Petersburg, Russia
}

\author{
Corresponding author: \\ Kuznetsov Alexandr A., \\ Maternity Clinic № 17, \\ Lesnozavodskaya str. 4/1, Saint Petersburg, \\ Russia, 193174. \\ E-mail: a.a.kuznetsov03@gmail.com \\ Received 25 February 2019; accepted \\ 01 September 2019.
}

\begin{abstract}
Single intrauterine fetal demise (sIUFD) in multiple pregnancy occurs with frequency from 3.7 up to $6.8 \%$ and is associated with an risk of premature birth, death of cotwin and high morbidity and mortality rates in newborns. The time of sIUFD and type of twin gestation would determine perinatal outcomes. The rate of prenatal death of the co-twin is different and depend on the type of multiple pregnancy, accounting $4 \%$ for dichorionic and $12 \%$ in monochorionic pregnancies. However, the correlation between the type of chorionicity, delivery time and the frequency of preterm delivery is not clearly established. The risk of neurological complications in newborns after sIUFD fluctuate significantly in case of the type of chorionicity and could achieve $18 \%$ in monochorionic twins and only $1 \%$ in dichorionic twins. The paper was discussed the main reasons for sIUFD in multiple pregnancy, rather pathophysiological aspects of perinatal morbidity and mortality for cotwin was also discussed. The management of complications, methods of their correction, optimal methods and time of delivery in case of sIUDF in multiple pregnancies was presented.
\end{abstract}

Key words: single twin demise, intrauterine fetal death, multiple pregnancy.

For citation: Kuznetsov AA, Romanovsky AN, Shlykova AV et al. Single fetal demise in multiple pregnancy. Translyatsionnaya meditsina=Translational Medicine. 2019;6(5):31-38. (In Russ.) 
Список сокращений: МХДА - монохориальная диамниотическая, СГОП - синдром гибели одного плода.

\section{Введение}

Широкое внедрение вспомогательных репродуктивных технологий с целью преодоления бесплодия привело к двукратному увеличению частоты многоплодной беременности, которая достигает в популяции величины в $2 \%$. При этом частота многоплодия у женщин, беременность которых наступила после применения методов вспомогательных репродуктивных технологий, достигает $35 \%$ [1].

Одним из осложнений многоплодной беременности является синдром гибели одного плода (СГОП), частота которого варьирует в пределах от 3,7 до $6,8 \%[2,3,4]$. СГОП при многоплодии может происходить на любом сроке беременности, но наиболее часто имеет место в первом ее триместре. Одним из ведущих факторов, который определяет заболеваемость и смертность среди вторых выживших плодов при многоплодной беременности, является тип ее хориальности и амниональности. Так антенатальная гибель второго плода регистрируется у $12 \%$ беременных при монохориальном и в $4 \%$ при дихориальном типе многоплодия. При этом после СГОП риск развития неврологических нарушений значительно выше среди новорожденных из монохориальной пары и составляет $18 \%$ по сравнению с $1 \%$ - при дихориальной двойне [2]. Дихориальный тип многоплодия характеризуется наличием двух самостоятельных систем гемоциркуляции плодов, что исключает их непосредственную взаимосвязь в виду отсутствия между этими системами сосудистых анастомозов, даже при наличии «слившихся» плацент. При монохориальном типе многоплодия в плаценте всегда имеются анастомозы между сосудистыми системами плодов, среди них выделяют три типа: поверхностные - артерио-артериальные и вено-венозные и глубокие - артерио-венозные. Тип хориальности и амниональности должны быть установлены при ультразвуковом исследовании уже в первом триместре многоплодной беременности. Они являются ведущими параметрами, которые определяют дальнейшую тактику ведения беременности, особенно при выявлении у плодов аномалий развития, возникновении у них критических состояний, а так же при гибели одного плода из двойни [5].

Причины СГОП могут быть неспецифическими для многоплодия, схожими с таковыми при одноплодной беременности или могут быть специфическими, характерными только для многоплодной беременности [5]. К неспецифическим причинам относят генетические или анатомические аномалии у плодов, частичную и непрогрессирующую отслойку плаценты, развитие критической плацентарной недостаточности и синдрома замедления роста плода, формирование истинного узла пуповины и другие. К специфическим причинам гибели одного плода при многоплодной беременности относят коллизию петель пуповины при монохориальной моноамниотической двойне, фето-фетальный трансфузионный синдром и синдром обратной артериальной перфузии при монохориальном диамниотическом многоплодии [6, 7].

\section{Синдром гибели одного плода при дихориальном типе многоплодия}

СГОП при дихориальной двойне происходит в три раза реже по сравнению с монохориальным типом многоплодия [2]. Учитывая отсутствие сосудистых анастомозов в плодовой части плацент и непосредственной взаимосвязи между системами гемоциркуляции плодов при дихориальном типе многоплодия, гибель одного плода не оказывает прямого воздействия на дальнейшее развитие второго плода. Таким образом, при отсутствии факторов со стороны организма матери, которые могут быть причиной гибели одного плода из дихориальной двойни, после исключения признаков нарушения жизнедеятельности второго плода, показания для каких-либо вмешательств в течение беременности отсутствуют [6]. В литературе отсутствуют достоверные данные о возможном развитии синдрома диссеминированного внутрисосудистого свертывания у беременной женщины при СГОП, в связи с этим проведение дополнительного гематологического обследования пациентки при этом осложнении беременности не показано [8]. При дальнейшем ведении беременности необходимо проведение динамической оценки функционального состояния второго развивающегося плода вплоть до его рождения. При этом в случае отсутствия дополнительных осложнений беременности показания для досрочного родоразрешения или родоразрешения путем операции кесарева сечения пациентки с СГОП отсутствуют [5].

При наличии у матери резус отрицательной принадлежности крови после установления диагноза СГОП ей показано введение анти-Д иммуноглобулина с целью профилактики развития резус-иммунизации [5].

Преждевременные роды являются основным угрожающим состоянием в отношении дальнейшего прогноза для выжившего плода при СГОП, развившегося при дихориальной двойне. Их частота еще до 34 недель беременности может достигать 
57 \% [9]. Ранние преждевременные роды у новорожденных с низкой массой тела обуславливают увеличение частоты развития у них респираторного дистресс-синдрома, тяжелых внутрижелудочковых кровоизлияний и перивентрикулярной лейкомаляции головного мозга, что определяет высокий уровень неонатальной заболеваемости и неонатальной смертности [10].

\section{Гибель одного плода при монохориальном типе многоплодия}

Около 60 \% всех случаев СГОП при многоплодии происходит при монохориальным типе плацентации, при этом вероятность гибели второго плода и развития неврологических осложнений у живорожденного новорожденного значительно выше по сравнению с таковой при дихориальном типе многоплодия [11].

В отличие от дихориальной плацентации сосудистая сеть монохориальной плаценты имеет в своем составе несколько типов анастомозов, объединяющих циркуляцию крови двух плодов: поверхностные - артерио-артериальные и вено-венозные, а также глубокие - артериовенозные. Для объяснения причин развития осложнений у выжившего после СГОП второго плода из монохорильной двойни наибольшее распространение получила гипотеза гемодинамического шунтировании. R. Bajoria и соавторы (1999) показали, что при отсутствии клинических проявлений фето-фетального трансфузионного синдрома перинатальная смертность выше среди беременных, в плацентах которых имели место крупные поверхностные артерио-артериальные и вено-венозные сосудистые анастомозы, по сравнению с теми, в плацентах которых преобладали глубокие артериовенозные анастомозы [7, 12]. При СГОП при монохориальном типе плацентации из системы гемоциркуляции выжившего плода через открытые артерио-артериальные и вено-венозные анастомозы сосудов плаценты, имеющие низкую резистентность кровотоку, происходит острая трансфузия крови в посмертно расширенную сосудистую сеть погибшего плода. Подобная трансфузия может приводить к развитию выраженной анемизации, вторичной гипотензии и гипоперфузии ткани головного мозга выжившего плода [3]. Справедливость данной гипотезы находит подтверждение в результатах исследования образцов крови плодов, полученной при диагностическом кордоцентезе у пациенток, имевших монохориальную диамниотическую двойню. Так U. Nicolini и соавторы (1998) выполнили исследование гематологических показателей у плодов при монохориальной диамниотической двойне, осложненной фето-фетальным трансфузионным синдромом неза- долго до и в течение 24 часов от момента внутриутробной гибели одного из плодов. В анализе крови всех четверых выживших плодов гематокрит был значительно снижен по сравнению с его значениями, установленными до гибели первого плода, и составлял в среднем $21 \%$ (17-29\%) [13]. K. Okamura и соавторы (1994) так же установили после гибели одного плода развитие анемии у пяти выживших плодов беременных женщин при монохориальной диамниотической (МХДА) двойне [14].

Современная пренатальная диагностика гемолитической болезни плода основана на неинвазивной доплерометрической оценке показателя максимальной систолической скорости кровотока в средней мозговой артерии плода, величина которого во втором и третьем триместрах беременности имеет выраженную корреляцию с величиной уровня гемоглобина и гематокрита в крови плода, полученной при диагностическом кордоцентезе. Данный метод нашел широкое применение и для оценки наличия и определения степени тяжести анемии у выжившего плода из монохориальной двойни при СГОП $[15,16]$.

Вероятность гибели второго плода в случае СГОП при монохориальной диамниотической двойне в пять раз выше по сравнению с таковой при дихориальном типе многоплодия и составляет $15 \%$ [17]. S. C. Hillman и соавторы (2011) проанализировали данные из 22 источников, в которых были представлены перинатальные исходы 343 случаев СГОП. Исследование показало, что после гибели одного плода при монохориальном типе плацентации вероятность неврологических осложнений у выжившего новорожденного составляет 26 \%, что в 13 раз превышает таковую при дихориальном типе плацентации, составляющую лишь 2 \% [2].

\section{СГОП в первом триместре беременности}

Применение ультразвуковых приборов с высокой разрешающей способностью позволило уже на ранних этапах беременности определять точное число плодных яиц и эмбрионов в полости матки. Это дало возможность установить, что их число, установленное в первом триместре беременности, значительно превышает число новорожденных, родившихся в результате многоплодной беременности. Это несоответствие числа плодных яиц в полости матки в начале многоплодной беременности объясняется, в частности, возникновением так называемого феномена «исчезнувшего плода». Даже при выявлении на ранних сроках беременности сердечной деятельности у обоих эмбрионов на ранних сроках беременности вероятность рождения двойни составляет лишь 70 \% [18]. Считается, что при ди- 
хориальном типе многоплодия гибель одного плода во время первого триместра беременности не вызывает непосредственных осложнений в отношении дальнейшего развития второго плода. На сегодняшний день и при МХДА-двойне негативное влияние СГОП на ранних сроках беременности в отношении последующего развития второго плода так же не установлено. В настоящее время нет данных, сформированы и являются ли сосудистые анастомозы между циркуляциями эмбрионов в монохориальной плаценте на ранних этапах развития беременности функционально активными для обеспечения патологической трансфузии крови в сосудистое русло погибшего эмбриона в момент его гибели [5].

\section{СГОП до срока жизнеспособности плодов при МХДА}

При монохориальной плацентации высокая вероятность воздействия СГОП во втором триместре беременности на развитие выжившего плода обусловлена функционально активными поверхностными низко резистентными сосудистыми анастомозами между системами гемоциркуляции плодов. При нейросонографии возможность выявления повреждений структур развивающегося головного мозга второго плода зависит от периода времени, прошедшего с момента гибели первого плода. При СГОП выполнение нейросонографии позволяет исключить или заподозрить гипоплазию оптического нерва, мультикистозную лейкоэнцефаломаляцию, микроцефалию, порэнцефалию, гидроцефалию, а при ультразвуковом исследовании других органов плода - билатеральный некроз коркового слоя почек, микросомию и кожную аплазию [19]. R. M. Patten и соавторы (1989) показали, что нейросонография позволяет выявить первые признаки структурных изменений головного мозга выжившего плода не ранее 7 дней от момента СГОП [20].

Большинство исследователей считают, что с целью подтверждения и уточнения диагноза целесообразно проведение магнитно-резонансной томографии головного мозга развивающегося плода после 34 недели беременности. В случае антенатального подтверждения клинически значимых множественных повреждений центральной нервной системы плода этими двумя высокоинформативными методами исследования, их результаты могут служить основанием для перинатального обсуждения вопроca c пациенткой о возможном прерывании данной беременности по показаниям со стороны плода.

\section{СГОП в период жизнеспособности плодов}

СГОП при МХДА-двойне после достижения плодом периода жизнеспособности вызывает наи- большую сложность в определении дальнейшей тактики ведения данной беременности, поскольку возникает потенциальная дилемма между срочным родоразрешением, но с рождением глубоко недоношенного выжившего плода и пролонгированием беременности с возможным увеличением последующих рисков заболеваемости и смертности для выжившего плода в периоде новорожденности.

В настоящее время, по мнению большинства перинатологов, при отсутствии объективных данных о нарушении состояния выжившего плода дальнейшая консервативная тактика ведения беременности в сочетании с постоянным мониторингом его состояния считается наиболее предпочтительной [6].

В случае выявления признаков тяжелой анемии у выжившего плода при доплерометрии кровотока в средней мозговой артерии, с целью ее коррекции и пролонгирования беременности, возможно внутриутробное переливание плоду отмытых эритроцитов донора по аналогии с методом коррекции тяжелой анемии при гемолитической болезни плода. Однако считается, что данная операция эффективна лишь при ее проведении в первые сутки после СГОП.

M. V. Senat и соавторы (2002) провели внутриутробное переливание шестерым выжившим плодам в течение 24 часов от момента СГОП, у четверых из шести в последующем не было выявлено каких-либо неврологических отклонений от нормального развития в возрасте до одного года. У двух других плодов было выявлено наличие перивентрикулярной лейкомаляции [21]. Менее удачные результаты продемонстрировали S. Tanawattanacharoen и coавторы (2001), проведя в течение 24 часов после СГОП внутриутробное переливание анемизированным плодам у семи пациенток при МХДА-беременности. Два плода в этом исследовании погибли в течение 24 часов от момента внутриутробного переливания крови. У двух плодов, несмотря на проведенную внутриматочную коррекцию анемии, в последующем при проведении магнитно-резонансной томографии были выявлены тяжелые повреждения структур головного мозга, в связи с чем после проведения перинатального консилиума беременность у этих пациенток была прервана. У одной пациентки произошли преждевременные роды в 28 недель беременности, спустя неделю от момента внутриутробного переливания, и ее новорожденный погиб в течение первых суток. Только у двух новорожденных из семи пациенток не было выявлено каких-либо неврологических отклонений и структурных повреждений головного мозга [22].

Таким образом, внутриутробное переливание отмытых донорских эритроцитов выжившему плоду из монохориальной диамниотической двойни 
является эффективным методом коррекции выявленной анемии у плода. Однако эффективность коррекции анемии плода в отношении последующего неврологического развития новорожденного вероятно зависит от времени, прошедшего с момента СГОП до выполнения внутриутробного переливания крови плоду. На основании нашего опыта, возможность предотвращения повреждений структур головного мозга выжившего плода с использованием данного метода требует проведения дополнительных исследований [5].

Преждевременные роды - частое осложнение при СГОП, так А. Fichera и соавторы (2009) показали, что средний срок родоразрешения при этом осложнении МХДА-двоен в среднем составил 36 $(28,4-40,2)$ недель беременности [23], и большинство пациенток было родоразрешено в течение трех недель от момента гибели одного из плодов [24]. Учитывая достаточно высокую вероятность досрочного родоразрешения в этой группе беременных женщин, принципиально важным является своевременное проведение курса антенатальной профилактики респираторного дистресс-синдрома новорожденного.

В случае выявления СГОП при доношенном сроке беременности, вне зависимости от типа плацентации, показано срочное родоразрешение ввиду высоких рисков осложнений в отношении второго плода. Метод родоразрешения должен быть обсужден в каждом случае индивидуально, при этом роды через естественные родовые пути не противопоказаны при условии наличия возможности осуществления постоянного мониторинга состояния плода. Если первым предлежит погибший плод, процесс родов второго плода может быть осложнен и может привести к увеличению интранатальных рисков в отношении родоразрешения второго плода, в таком случае целесообразно обсуждение вопроса об оперативном родоразрешении путем операции кесарева сечения.

\section{Заключение}

СГОП при многоплодии сочетается со значительным повышением частоты заболеваемости и смертности в отношении второго плода. Определяющими факторами в отношении исходов беременности для второго плода являются хориальность и срок беременности на момент СГОП. При монохориальном типе многоплодия в виду наличия сосудистых анастомозов в плаценте, которые создают условия для шунтирования крови в сосудистое русло погибшего плода и развития выраженной анемии у второго плода, показатели перинатальной заболеваемости и смертности у последнего после его рождения мно- гократно превышают таковые при дихориальном типе плацентации. Для исключения повреждений центральной нервной системы второго плода при МХДА-двойне показано проведение МРТ и нейросонографии в 34 недели беременности после завершения процесса основной миграции нейронов в коре головного мозга. Частота преждевременных родов при СГОП значимо не различается в группах монохориального и дихориального типов многоплодия [23]. При отсутствии осложнений после СГОП целесообразно родоразрешение в доношенном сроке беременности. При необходимости досрочного родоразрешения рекомендовано своевременное проведение курса антенатальной профилактики респираторного дистресс-синдрома новорожденных. При резус отрицательной принадлежности крови матери после установления СГОП показано введение анти-Д иммуноглобулина с целью профилактики резус-иммунизации. Пациенты с синдромом гибели одного плода при многоплодной беременности должны наблюдаться в специализированных центрах третьего уровня.

\section{Конфликт интересов / Conflict of interest}

Авторы заявили об отсутствии потенциального конфликта интересов. / The authors declare no conflict of interest.

\section{Список литературы / References}

1. Blickstein I, Keith LG. Multiple pregnancy: epidemiology, gestation, and perinatal outcome. CRC Press, 2005. p. 976.

2. Hillman SC, Morris RK, Kilby MD. Co-twin prognosis after single fetal death: a systematic review and metaanalysis. Obstet Gynecol. 2011;118(4):928-940.

3. Woo HH, Sin SY, Tang LC. Single foetal death in twin pregnancies: review of the maternal and neonatal outcomes and management. Hong Kong Med J. 2000;6(3):293300.

4. Kilby MD, Govind A, O'Brien PM. Outcome of twin pregnancies complicated by a single intrauterine death: a comparison with viable twin pregnancies. Obstet Gynecol. 1994;84(1):107-109.

5. Mikhailov AV, Romanovsky AN, Shlykova AN et al. Single fetal death in multiple pregnancy, in: the fetus and neonates as the patients. SPb.: Petropolis, 2015: 931-935. In Russian [Михайлов А. В., Романовский А. Н., Шлыкова А. Н. и др. Гибель одного из плодов при многоплодии. В кн: Плод и новорожденный как пациенты. Спб.: Издательский дом Петрополис, 2015: 931-935].

6. Blickstein I, Perlman S. Single fetal death in twin gestations. J Perinat Med. 2013;41(1):65-69.

7. Mikhailov AV, Romanovsky AN, Kuznetsov AA et al. The main complications of fetoscopic laser coagulation of placental anastomoses in twin-to-twin transfusion syndrome. Tavricheskij mediko-biologicheskij vestnik=Tauride Medical and Biological Bulletin. 2018;21(2):189-194. In Russian [Михайлов А. В., Романовский А. Н., Кузнецов А. А. и др. Основные осложнения операции фетоскопической 
лазерной коагуляции анастомозов плаценты при фето-фетальном трансфузионном синдроме. Таврический медико-биологический вестник. 2018;21(2):189-194].

8. Romero R, Duffy TP, Berkowitz RL et al. Prolongation of a preterm pregnancy complicated by death of a single twin in utero and disseminated intravascular coagulation. Effects of treatment with heparin. N Engl J Med. 1984;310(12):772-774.

9. Ong SS, Zamora J, Khan KS et al. Prognosis for the co-twin following single-twin death: a systematic review. BJOG. 2006;113(9):992-998.

10. Kusuda S, Fujimura M, Sakuma I et al. Morbidity and mortality of infants with very low birth weight in Japan: center variation. Pediatrics. 2006;118(4):e1130-1138.

11. Santema JG, Swaak AM, Wallenburg HC. Expectant management of twin pregnancy with single fetal death. Br J Obstet Gynaecol. 1995;102(1):26-30.

12. Bajoria R, Wee LY, Anwar S et al. Outcome of twin pregnancies complicated by single intrauterine death in relation to vascular anatomy of the monochorionic placenta. Hum Reprod. 1999;14(8):2124-2130.

13. Nicolini U, Pisoni MP, Cela E et al. Fetal blood sampling immediately before and within 24 hours of death in monochorionic twin pregnancies complicated by single intrauterine death. Am J Obstet Gynecol. 1998;179(3Pt1):800 803.

14. Okamura K, Murotsuki J, Tanigawara S et al. Funipuncture for evaluation of hematologic and coagulation indices in the surviving twin following co-twin's death. Obstet Gynecol. 1994;83(6):975-978.

15. Nakata $M$, Sumie M, Murata S et al. A case of monochorionic twin pregnancy complicated with intrauterine single fetal death with successful treatment of intrauterine blood transfusion in the surviving fetus. Fetal Diagn Ther. 2007;22(1):7-9.

16. Mari G, Deter RL, Carpenter RL et al. Noninvasive diagnosis by doppler ultrasonography of fetal anemia due to maternal red-cell alloimmunization. Collaborative group for doppler assessment of the blood velocity in anemic fetuses. N Engl J Med. 2000;342(1):9-14.

17. Shek NW, Hillman SC, Kilby MD. Single-twin demise: pregnancy outcome. Best Pract Res Clin Obstet Gynaecol. 2014;28(2):249-263.

18. Mikhailov A, Romanovsky A. Multiple pregnancy under ultrasound umbrella. Donald School Journal of U1trasound in Obstetrics and Gynecology. 2011;5(3):219-230.

19. Murphy KW. Intrauterine death in a twin: implications for the survivor. In: Multiple pregnancy. London: RCOG Press, 1995:218-230.

20. Patten RM, Mack LA, Nyberg DA et al. Twin embolization syndrome: prenatal sonographic detection and significance. Radiology. 1989;173(3):685-689.

21. Senat MV, Bernard JP, Loizeau S et al. Management of single fetal death in twin-to-twin transfusion syndrome: a role for fetal blood sampling. Ultrasound Obstet Gynecol. 2002;20(4):360-363.

22. Tanawattanacharoen S, Taylor MJ, Letsky EA et al. intrauterine rescue transfusion in monochorionic multiple pregnancies with recent single intrauterine death. Prenat Diagn. 2001;21(4):274-278.

23. Fichera A, Zambolo C, Accorsi P et al. Perinatal outcome and neurological follow up of the cotwins in twin pregnancies complicated by single intrauterine death. Eur J Obstet Gynecol Reprod Biol. 2009;147(1):37-40.
24. D'Alton ME, Newton ER, Cetrulo CL. Intrauterine fetal demise in multiple gestation. Acta Genet Med Gemellol (Roma). 1984;33(1):43-49.

\section{Информация об авторах:}

Кузнецов Александр Александрович, врач родильного отделения СПб ГБУЗ «Родильный дом № 17», аспирант кафедры акушерства, гинекологии и неонатологии ФГБОУ ВО ПСПбГМУ им. И. П. Павлова Минздрава России;

Романовский Артем Николаевич, врач родильного отделения СПб ГБУЗ «Родильный дом № 17», ассистент кафедры репродуктивного здоровья женщин ФГБОУ ВО СЗГМУ им. И. И. Мечникова Минздрава России, ассистент кафедры акушерства, гинекологии и репродуктологии медицинского факультета СПбГУ;

Шлыкова Анна Вячеславовна, врач родильного отделения СПб ГБУЗ «Родильный дом № 17», заочный аспирант кафедры акушерства и гинекологии имени С. Н. Давыдова ФГБОУ ВО СЗГМУ им. И. И. Мечникова Минздрава России;

Каштанова Татьяна Александровна, заведующий отделением пренатальной диагностики СПб ГБУЗ «Родильный дом № 17»;

Шман Вера Валерьевна, заведующий родильным отделением СПб ГБУЗ «Родильный дом № 17»;

Кянксеп Инна Викторовна, врач отделения пренатальной диагностики СПб ГБУЗ «Родильный дом № 17 »;

Мовчан Вероника Евгеньевна, клинический ординатор кафедры акушерства и гинекологии имени С. Н. Давыдова ФГБОУ ВО СЗГМУ им. И. И. Мечникова Минздрава России;

Державина Надежда Евгеньевна, заместитель главного врача по медицинской части СПб ГБУЗ «Родильный дом № 17»;

Савельева Анна Антоновна, врач отделения пренатальной диагностики СПб ГБУЗ «Родильный дом № 17»;

Овсянников Филипп Андреевич, к.м.н, врач - акушер-гинеколог ФГБУ «НМИЦ им. В. А. Алмазова» Минздрава России;

Михайлов Антон Валерьевич, д.м.н., профессор, главный врач СПб ГБУЗ «Родильный дом № 17»; заведующий кафедрой репродуктивного здоровья женщин ФГБОУ ВО СЗГМУ им. И. И. Мечникова Минздрава России; главный внештатный специалист по акушерству и гинекологии Северо-Западного федерального округа Министерства здравоохранения Российской Федерации

\section{Author information:}

Kuznetsov Alexander A., Doctor of the Maternity Ward, Maternity Clinic № 17, PhD Student of Obstetrics and Gynecology Department, FSBEI HE I. P. Pavlov SPbSMU MOH Russia;

Romanovsky Artem N., Doctor of the Maternity Ward, Maternity Clinic № 17, Assistant of Department of Women’s Reproductive Health, North-Western State Medical University named after I. I. Mechnikov, Assistant of Department of Obstetrics, Gynecology and Reproductology, St. Petersburg State University;

Shlykova Anna V., Doctor of the Maternity Ward, Maternity Clinic №1 7; PhD Student of Obstetrics and Gyne- 
cology Department of S. N. Davydov, North-Western State Medical University named after I. I. Mechnikov;

Kashtanova Tatiana A., Head of the Department of Prenatal Diagnostics, Maternity Clinic № 17;

Shman Vera V., Head of Delivery Department, Maternity Clinic № 17;

Kyanksep Inna V., Doctor of Department of Prenatal Diagnostics, Maternity Clinic № 17;

Movchan Veronika E., Resident of Obstetrics and Gynecology Department of S. N. Davydov, North-Western State Medical University named after I. I. Mechnikov;

Derzhavina Nadegda E., Subchief of Maternity Clinic № 17 in Medicine;

Savel'eva Anna A., MD, Doctor of Department of Prenatal Diagnostics, Maternity Clinic № 17;

Ovsyannikov Fillip A., PhD, Obstetrician-Gynecologist, Almazov National Medical Research Centre;

Mikhailov Anton V., Dr. Sc., Professor, Chief of Maternity Clinic № 17, Chief of Department of Women's Reproductive Health, North-Western State Medical University named after I. I. Mechnikov, Chief Obstetrician-Gynecologist of the Ministry of Health of the Russian Federation in Saint Petersburg and the North-West Federal District. 